\title{
Da operação de manutenção de paz à cooperação técnica: as iniciativas brasileiras para a paz em Moçambique (1992-2010)
}

\author{
From peacekeeping operations to technical cooperation: \\ the Brazilian peace initiatives in Mozambique (1992-2010)
}

DOI: $10.5752 / P .2317-773 X .2018 v 6 . n 3 . p 47$

Thaise Kemer ${ }^{1}$
Alexsandro Eugenio Pereira²

Recebido em: 10 de novembro de 2017

Aprovado em: 14 de maio de 2018

\section{RESUMO}

Esse artigo analisa a participação brasileira nas iniciativas das Nações Unidas no processo de paz de Moçambique e argumenta que a atuação do Brasil no contexto moçambicano apresentou limites relativamente à associação entre a construção da paz e a promoção do desenvolvimento. Para evidenciar esse argumento, o artigo examinou a participação do Brasil no contexto da Operação das Nações Unidas em Moçambique (ONUMOZ) e analisou os acordos de cooperação técnica entre Brasil e Moçambique entre 1992 e 2010. Com base nessa análise, evidenciou que não houve continuidade entre a participação do Brasil na ONUMOZ e os acordos bilaterais de cooperação técnica entre Brasil e Moçambique. Durante o governo Fernando Henrique Cardoso apenas cinco acordos de cooperação bilateral foram implementados. Esse número foi ampliado no governo Lula. A análise qualitativa desses dados evidencia que a promoção do desenvolvimento esteve mais associada a decisões específicas de cada governo do que a uma política externa brasileira orientada à construção da paz, a qual demandaria a intensificação desses acordos após o término da ONUMOZ como forma de oferecer condições estruturais para a paz aos moçambicanos.

Palavras-chave: Paz; Desenvolvimento; Análise de Política Externa.

\section{Abstract}

This article analyzes the Brazilian participation in the initiatives of the United Nations in the peace process in Mozambique and argues that the Brazilian initiatives in the Mozambican context was limited in terms of the association between peacebuilding and development. In order to highlight this argument, the paper examines the participation of Brazil in the context of the United Nations Operation in Mozambique (UNOMOZ) and reviews the technical cooperation agreements between Brazil and Mozambique between 1992 and 2010. Based on this analysis, it is showed that there was no continuity between Brazil's participation in UNOMOZ and the bilateral technical cooperation
1. Doutoranda em Ciência Política pela Universidade Federal do Paraná (UFPR) e Mestre em Ciência Política pela mesma instituição. Pesquisadora do Núcleo de Pesquisa em Relações Internacionais (NEPRI/UFPR) e do Núcleo de Estudos para a Paz (UNILA). Possui Pós-Graduação em Relações Internacionais pelo Instituto Universitário Cândido Mendes do Rio de Janeiro (2013). Curitiba/Brasil ORCID: 0000-0002-6779-8972

2. Possui graduação em Ciências Sociais pela Universidade Federal do Paraná (1994), Mestrado e Doutorado em Ciência Política pela Universidade de São Paulo (1998 e 2003). Atualmente é Professor Associado do Departamento de Ciência Política e dos Programas de Pós-Graduação em Ciência Política e em Políticas Públicas da Universidade Federal do Paraná. É coordenador do Núcleo de Pesquisa em Relações Internacionais (NEPRI/UFPR), Editor-Chefe da Revista Conjuntura Global e pesquisador da área de Ciência Política. Curitiba/Brasil ORCID: 0000-0002-9613-4702 
between Brazil and Mozambique. While the government of Fernando Henrique Cardoso implemented five bilateral cooperation agreements, the government of Lula increased the bilateral cooperation projects to 49 . Based on these data, the paper evinces that the promotion of development was mainly associated with specific government decisions, in detriment of a Brazilian foreign policy geared to peacebuilding, which would require the intensification of such agreements after the end of the UNOMOZ, as a way to offer structural conditions for peace in Mozambique.

key words: Peace; Development; Foreign Policy Analysis.

Introdução

O presente artigo analisa as iniciativas do Brasil para a promoção da paz em Moçambique, no período compreendido entre a implementação da Operação das Nações Unidas em Moçambique (ONUMOZ), em 1992, a qual contou com a participação do Brasil, e 2010, último ano do segundo mandato de Luís Inácio Lula da Silva (20032010) como presidente brasileiro. Esse período permite analisar a política externa brasileira, compreendendo dois momentos: a participação brasileira no contexto da ONUMOZ; e os projetos brasileiros de cooperação para o desenvolvimento com Moçambique, realizados após o término dessa missão.

$\mathrm{O}$ artigo debate a seguinte questão: em que medida as políticas brasileiras para a promoção da paz em Moçambique estiveram relacionadas ao fortalecimento do desenvolvimento nesse país, no período entre 1992 e 2010? Para operacionalizar a pesquisa, utiliza-se o conceito de peacebuilding, segundo o qual a paz implica não apenas a cessação da violência física, mas também o provimento de "justiça social” (GALTUNG, 1976, p. 297-298). O conceito de justiça social, por sua vez, relaciona-se não apenas à presença de estruturas sociais - como o acesso a sistemas de saúde e de educação -, mas também à distribuição equânime de poder e de recursos, de forma a permitir que os indivíduos possam alcançar a totalidade de suas potencialidades (GALTUNG, 1976, p. 297-298; KEMER et al., 2016, p. 138-139). O conceito de peacebuilding foi criado por Johan Galtung, um dos fundadores do campo dos Estudos para a Paz (Peace Studies), durante a década de 1970, e foi internalizado no contexto das Nações Unidas no documento "Uma Agenda para a Paz”, do Secretário-Geral Boutros Boutros-Ghali (A/47/277, 1992). Com a ideia de peacebuilding, houve o fortalecimento da noção de desenvolvimento no contexto das Nações Unidas (KEMER et al., 2016, p. 139). De acordo com o primeiro relatório sobre o Desenvolvimento Humano da ONU em 1990, o desenvolvimento tem como objetivo básico "(...) criar um ambiente que habilite as pessoas a desfrutarem de vidas longas, saudáveis e criativas" (PNUD, 1990, p. 9; MACHADO; PAMPLONA, 2008, p. 62).

Para compreender a atuação do Brasil para a promoção da paz em Moçambique no período entre 1992 e 2010, o presente artigo considera, para o recorte temporal selecionado, os diferentes entendimentos sobre a noção de desenvolvimento apresentados pelos governos do Brasil nesse período. Assim, verifica-se que a Análise de Política Externa (APE) torna-se imprescindível para o debate do problema proposto, uma vez 
que, de acordo com Milani e Pinheiro (2013), a compreensão das mudanças na política interna permite um entendimento mais amplo sobre a política externa do Brasil, pois sua formulação e implementação estão inseridas na dinâmica das escolhas de governo (MILANI; PINHEIRO, 2013). Dessa forma, a política externa implementada pelos diferentes governos brasileiros torna-se relevante para a análise, com foco particular nos governos de Fernando Henrique Cardoso (FHC) (1995-2002) e Luís Inácio Lula da Silva (2003-2010), cujos mandatos ocuparam a maior parte do recorte temporal selecionado. A análise da política interna nacional oferece, portanto, elementos que permitem problematizar as iniciativas da política externa brasileira para a promoção da paz em Moçambique, para a qual a ideia de desenvolvimento, operacionalizada de maneiras distintas durante o período selecionado para o artigo, assume um papel fundamental.

O artigo argumenta que a atuação do Brasil no contexto moçambicano apresentou limites relativamente à associação entre construção da paz e promoção do desenvolvimento. Esses limites referem-se não apenas às características do mandato da ONUMOZ, voltado, principalmente, ao monitoramento do desarmamento e do cessar-fogo em Moçambique, mas também da política externa brasileira em matéria de desenvolvimento, tendo em vista as distintas orientações dos governos de FHC (1995-2002) e de Lula (2003-2010) nessa temática. Nesse sentido, a análise das iniciativas do Brasil para a paz em Moçambique revela uma relativa dissociação entre a promoção da paz e a promoção do desenvolvimento, pois: (1) no governo de FHC, não houve projetos de cooperação bilateral em diversos temas centrais para a promoção do desenvolvimento, como nas áreas da saúde, da agricultura, da capacitação profissional e da cultura e; (2) do ponto de vista quantitativo, a comparação entre os períodos FHC e Lula revelou grande disparidade quanto ao número dos projetos realizados - se, por um lado, o governo FHC implementou cinco acordos de cooperação bilateral, por outro, esse número foi ampliado para quarenta e nove no governo de Lula. Assim, esses dados sugerem que a promoção do desenvolvimento por meio de projetos de cooperação bilateral variou conforme as escolhas políticas dos governos de FHC e de Lula em matéria de paz e de desenvolvimento. Assim, o cerne do presente artigo é, precisamente, problematizar a ação do Brasil para a promoção da paz, de forma a considerar não apenas as linhas de continuidade existentes sobre esse tema no plano retórico, mas, também, as diferentes operacionalizações do duo paz-desenvolvimento no terreno moçambicano.

Nesse contexto, o artigo evidencia que os governos de FHC e de Lula apresentaram perspectivas distintas relativamente ao conceito de desenvolvimento. Considera-se, aqui, o argumento de Marcelo Passini Mariano e de Haroldo Ramanzini Júnior (2012), para os quais esse conceito pode variar de acordo com os diferentes governos responsáveis pela condução da política externa brasileira em um dado período. Consequentemente, no caso de Moçambique, as iniciativas brasileiras para a paz estiveram associadas, num primeiro momento, à operacionalização da ONUMOZ, cujo mandato previa, sobretudo, o 
monitoramento do desarmamento e do cessar-fogo em Moçambique. Num segundo momento, a ampliação dos esforços brasileiros para promover a vinculação entre desenvolvimento e paz por meio do incremento dos projetos de cooperação bilateral ocorreu, de forma mais intensa, apenas no governo Lula, a partir de 2003. Essa constatação revela que houve descontinuidades entre as ações dos governos de FHC e de Lula no que se refere à articulação entre paz e desenvolvimento, haja vista que a construção da paz "duradoura" requereria, da parte do Brasil, uma agenda de política externa capaz de viabilizar, por meio de projetos de cooperação, esse desenvolvimento, após a conclusão de sua participação na ONUMOZ.

No que se refere à política externa, João Paulo $S$. Alsina Júnior (2017, p.2) sugere uma contribuição interessante. Esse autor apresenta o conceito de "grande estratégia" ("grand strategy"), que remete à capacidade de um Estado de articular diferentes políticas públicas, de forma a considerar as oportunidades e as condicionantes internacionais na busca de seus objetivos. Porém, a avaliação da coerência da "grande estratégia" de um Estado somente é pertinente durante o período em que uma dada estratégia é considerada válida pelos tomadores de decisão estatais. Nesse sentido, Alsina Jr. (2017, p. 2) afirma que mudanças de tomadores de decisão afetam a estratégia adotada por um país em matéria de política externa. Dessa forma, as descontinuidades verificadas no presente artigo na agenda de peacebuilding em Moçambique podem ser compreendidas à luz do contexto particular dos governos analisados. Essa perspectiva evidencia a tensão existente entre a política externa brasileira e o processo de pacificação do conflito moçambicano, haja vista que, enquanto a primeira pode variar de acordo com os tomadores de decisão em exercício, o segundo requer ações caracterizadas não apenas pela coordenação entre ações militares e de cooperação, mas, também, pautadas por um horizonte temporal mais amplo, de forma a atender as necessidades de desenvolvimento específicas da população local.

Para desenvolver o argumento do artigo, a metodologia adotada consistiu na pesquisa bibliográfica de fontes nacionais e internacionais, além da sistematização e da análise dos acordos de cooperação técnica entre Brasil e Moçambique, os quais estão disponíveis no Sistema de Atos Internacionais do Ministério das Relações Exteriores do Brasil (MRE, 2017b). No seu desenvolvimento, o artigo está dividido em três seções, além da introdução e da conclusão. Na primeira apresenta-se breve contextualização histórica sobre o Acordo Geral de Paz de 1992 e a implementação da ONUMOZ, que ocorreu entre 1993 e 1994. Na segunda seção evidencia-se a participação do Brasil no contexto da ONUMOZ, de forma a elucidar a forma dessa participação e as motivações brasileiras. Por fim, na última seção, os acordos de cooperação técnica entre Brasil e Moçambique, entre 1992 e 2010, são analisados. Assim, com base no estudo de caso do contexto moçambicano, o artigo contribui para o aprofundamento do debate sobre o papel do Brasil, enquanto parte do Sul Global, na promoção da paz internacional. 
Moçambique: do conflito à operação de manutenção

da paz das Nações Unidas de 1992

A presente seção contextualiza historicamente o conflito moçambicano e a operacionalização da missão de manutenção de paz das Nações Unidas nesse país. As causas desse conflito, que envolveu disputas entre os dois principais partidos políticos do país, a Resistência Nacional Moçambicana (RENAMO) e a Frente de Libertação de Moçambique (FRELIMO), ultrapassam fatores políticos e residem na intersecção de disputas por poder internas, regionais e internacionais. Como destacou Malaquias (1998, p. 1), o acordo de paz de Moçambique foi elaborado com o objetivo de encerrar conflitos sangrentos e prolongados, que foram legados pela Guerra Fria e pelo apartheid.

As raízes históricas desse conflito relacionam-se com o colonialismo português em Moçambique (VISENTINI, 2012, p. 89). De fato, em 1962, houve a formação do primeiro partido de oposição moçambicana a Portugal, a Frente de Libertação Nacional de Moçambique (FRELIMO) (RUPIYA, 1998, p. 10). Após 1970, Portugal passou a lutar contra a FRELIMO. Contudo, o contexto da Revolução dos $\mathrm{Cravos}^{3}$, que ocorreu em Portugal em 1974, e as discordâncias domésticas nesse país sobre a presença portuguesa em Moçambique, Guiné-Bissau e Angola, modificou o contexto moçambicano. Como consequência da Revolução dos Cravos em Portugal, houve a retirada de 60.000 soldados portugueses de Moçambique. Ainda no mesmo ano, o Acordo de Lusaka foi assinado e colocou fim ao colonialismo português em Moçambique (RUPIYA, 1998, p. 11).

Em 1975, Samora Machel, líder da FRELIMO, tornou-se o primeiro presidente moçambicano, e a FRELIMO tornou-se o centro do sistema unipartidário em Moçambique (RUPIYA, 1998, p. 12). Em 1977, a FRELIMO foi oficialmente transformada em um movimento Marxista-Leninista, o que deu condições para uma aproximação entre esse partido e a União das Repúblicas Socialistas Soviéticas (RUPIYA, 1998, p. 12). Segundo Rupiya (1998, p. 12-13), a despeito da agenda nacionalista da FRELIMO, o governo conferiu tratamento desigual a determinados grupos sociais, como foi o caso dos camponeses moçambicanos, os quais foram relegados a um segundo plano no contexto das políticas nacionais de Moçambique, em razão do foco do governo desse país nas fazendas estatais. Além disso, Rupiya afirmou que houve a marginalização das autoridades tradicionais, o que levou a um aumento das hostilidades entre a população e o governo e contribuiu para a escalada do conflito civil.

A principal oposição à FRELIMO foi a Resistência Nacional Moçambicana (RENAMO), formada, em 1977, pela Agência de Inteligência Nacional do Zimbábue (CIO) (RUPIYA, 1998, p. 13; REFWORLD, 2001). Essa agência promoveu a formação da RENAMO como um contraponto ao Presidente de Moçambique, Samora Machel, que apoiava o Exército de Libertação Nacional do Zimbábue (ZANLA), grupo de oposição desse país (BRITANNICA, 2017). Os objetivos da RENAMO, naquele contexto, eram desestabilizar o governo da FRELIMO e oferecer inteligência ao Exército de Libertação Nacional do Zimbábue, que estava operando nas fronteiras de Moçambique (RUPIYA, 1998, p. 13).
3. A Revolução dos Cravos foi um movimento iniciado em Portugal no dia 25 de abril de 1974 no qual o Movimento das Forças Armadas pôs fim a 48 anos de ditadura naquele país (VARELLA, 2012. p. 403). 
Em 1980, com a independência do Zimbábue, o controle da RENAMO foi transferido para a África do Sul, cujo objetivo era fazer oposição ao movimento armado sul-africano que estava lutando contra o apartheid (RUPIYA, 1998, p. 13). Além disso, a África do Sul também bloqueou o acesso ao mar que o Zimbábue tinha por meio de Moçambique, o que aumentaria o domínio exercido pela África do Sul no contexto regional (RUPIYA, 1998, p. 13).

Em 1984, o Pacto de Não-Agressão de Nkomati, que visava ao fim das hostilidades entre Moçambique e a África do Sul, foi assinado por esses países. No contexto desse pacto, esses Estados comprometeram-se a não oferecer apoio material aos movimentos de oposição presentes em cada um deles (CRAVINHO, 2004, p. 742). O governo sul-africano, contudo, ignorou o acordo e, em 1984, forças da RENAMO estavam presentes em todas as províncias de Moçambique (CRAVINHO, 2004, p. 742).

Após o Acordo de 1984, a RENAMO passou a adotar uma estratégia política baseada na utilização de recursos da população local e no ataque a infraestruturas nacionais, como construções públicas (RUPIYA, 1998, p. 13). Nesse sentido, uma das principais ações da RENAMO consistiu na destruição de estradas públicas, centros de saúde e escolas, como forma de atacar o governo da FRELIMO (RUPIYA, 1998, p. 13).

Em 1987, Joaquim Chissano, que assumiu a presidência de Moçambique no contexto do falecimento de Samora Machel, em 1986, iniciou um conjunto de reformas na FRELIMO, o que levou esse partido a deixar de ser marxista, no ano de 1989 (RUPIYA, 1998, p. 14). Naquele momento, a RENAMO também enfrentava o desafio de fazer a transição de um grupo militar para um partido político (RUPIYA, 1998, p. 14). Esse contexto formou a base para o Acordo Geral de Paz entre a RENAMO e o governo da FRELIMO em Moçambique, estabelecido em 1992 e composto por sete protocolos (RUPIYA, 1992, p. 14). Entre outros temas, os protocolos: (i) estabeleciam diretrizes para a organização de partidos políticos e das eleições moçambicanas; (ii) previam a formação da Força de Defesa Moçambicana, de caráter apartidário; (iii) estabeleciam mecanismos de supervisão do cessar-fogo; e (iv) afirmavam a necessidade da realização de uma conferência internacional de doadores para financiar o processo eleitoral e programas humanitários (GPA, 1992, p. 60).

Devido às persistentes violações ao cessar-fogo em várias áreas do país, o Conselho de Segurança estabeleceu, em 16 de dezembro de 1992, a Operação de Paz das Nações Unidas em Moçambique (ONUMOZ) (NAÇÕES UNIDAS, 1992b). O mandato da ONUMOZ incluiu aspectos políticos, eleitorais, militares e humanitários. No âmbito político, foi designado um Representante Especial para liderar uma Comissão de Monitoramento e de Supervisão do Acordo de Paz (ONUMOZ, 2017). Com relação às eleições nacionais, foi estabelecida a Divisão Eleitoral da ONUMOZ, responsável por monitorar o processo eleitoral e, também, por manter contato com o governo de Moçambique (ONUMOZ, 2017). No âmbito militar, a ONUMOZ foi incumbida de monitorar o cessar-fogo, a separação e a concentração das forças das partes envolvidas no conflito, a desmobilização dos combatentes, a coleta, armazenamento e destruição de armas, a retirada das forças estrangeiras e o desmantelamento de grupos 
militares armados privados e irregulares (ONUMOZ, 2017). Além disso, estabeleceu-se um componente da ONUMOZ para operações humanitárias (UNOHAC), que serviria tanto como um instrumento de reconciliação quanto como uma forma de apoiar o retorno de refugiados e de deslocados internos para seus lares (ONUMOZ, 2017).

Em razão dos atrasos na implementação das unidades militares da ONUMOZ, seu início ocorreu apenas em maio de 1993 (ONUMOZ, 2017), enquanto que as eleições moçambicanas foram atrasadas em um ano e ocorreram em outubro de 1994 (RUPIYA, 1998, p. 16). Nessas eleições, $85 \%$ dos 5,2 milhões de votantes registrados compareceram às urnas e reelegeram Joaquim Chissano como o Presidente de Moçambique. A FRELIMO, por sua vez, obteve a maioria dos assentos do Parlamento (129 dos 250 assentos disponíveis) (RUPIYA, 1998, p. 16-17). De acordo com Malaquias (1998, p. 1), a ONUMOZ, ao custo de cerca de um bilhão de dólares, constituiu uma missão de "sucesso", uma vez que a RENAMO se comprometeu a atuar de forma pacífica como a oposição da FRELIMO no Parlamento. Nesse contexto, os mais de 5.500 peacekeepers da ONUMOZ foram gradualmente retirados do país e a missão foi finalizada em janeiro de 1995 (MALAQUIAS, 1998, p. 3; ONUMOZ, 2017). Para corroborar essa afirmação de sucesso, Malaquias (1998, p. 3) afirma, também, que a ONUMOZ buscou: (i) aumentar a confiança e a cooperação entre a RENAMO e a FRELIMO; (ii) assegurar a aderência das partes ao acordo de paz; (iii) atuar na separação das facções rivais, na desmobilização de tropas e na coleta e destruição de armas; e (iv) oferecer assistência humanitária aos moçambicanos, o que incluiu a entrega de alimentos e a repatriação de refugiados e de deslocados internos.

Embora esses resultados aparentemente corroborem a ideia de "sucesso" da iniciativa das Nações Unidas para a paz em Moçambique (MALAQUIAS, 1998, p. 1), é relevante recordar, nesse contexto, os argumentos de Rob Jenkins (2013) sobre processos de peacebuilding. De acordo com esse autor, uma das questões que podem ser levantadas sobre as iniciativas das Nações Unidas para a paz se refere à duração desses processos (JENKINS, 2013, p. 24-28; KEMER et al., 2016, p. 144). Dado que não existe uma duração definida para a conclusão de um processo de paz e, ainda, que a paz vem sendo associada pelas Nações Unidas ao desenvolvimento, é possível afirmar que o término da ONUMOZ não trouxe, necessariamente, a paz para a sociedade moçambicana. Reppell et al. $(2016$, p. 9) afirmam, nesse sentido, que mais de vinte anos após o estabelecimento do Acordo Geral de Paz, mais de 14 milhões de pessoas em Moçambique vivem em condições de subdesenvolvimento, com menos de US\$1,25 por dia ${ }^{4}$. Além disso, o país ainda necessita de programas de apoio à reintegração de ex-combatentes na economia nacional (REPPELL et al., 2016, p. 9). Adicionalmente, após 2013, a violência entre os partidos RENAMO e FRELIMO tornou-se evidente no contexto político moçambicano. Segundo Bowker et al. (2017) e Jentzsch (2017), abusos de direitos humanos são cometidos por ambas as partes em conflito e, de acordo com a organização Médicos Sem Fronteiras (2016), mais de 5.800 refugiados moçambicanos ainda não têm acesso a condições humanitárias mínimas, na medida em que estão em abrigos superlotados, sem acesso a água potável e a
4. Segundo o Banco Mundial, a população total de Moçambique, em 2015, totalizava cerca de 28 milhões de habitantes (BANCO MUNDIAL, 2017). 
saneamento básico (MSF, 2016). Nesse contexto, é importante considerar a ênfase das Nações Unidas na inter-relação entre paz e desenvolvimento, evidenciada por meio do conceito de peacebuilding (A/47/277, 1992). Partindo dessa perspectiva, é possível afirmar que o processo de paz em Moçambique está, ainda, em curso (PBSO, 20Io; KEMER et al., 2016), na medida em que o país apresenta diversas carências em termos de estruturas sociais, como os déficits existentes em seus sistemas de educação, de saúde e de saneamento básico, entre outros (BANCO MUNDIAL, 2017).

Esses dados evidenciam a necessidade de ampliar a discussão sobre o "sucesso" do processo de paz moçambicano (REPPELL et al., 2016, p. 9; JENTZSCH, 2017). Para contribuir com esse debate, a próxima seção apresenta a perspectiva brasileira sobre o processo de paz moçambicano, analisando o papel do Brasil no contexto da ONUMOZ.

0 "jeitinho brasileiro" na Operação das Nações Unidas

em Moçambique (1993 a 1994): interesses e práticas

A presente seção analisa o processo de paz moçambicano a partir da perspectiva do Brasil, cujos objetivos, naquele contexto, foram avançar seus interesses nacionais no plano internacional e contribuir para o processo de paz moçambicano. Para elaborar essa análise, a seção centra-se na participação do Brasil na ONUMOZ, que ocorreu entre janeiro de 1993 e dezembro de 1994 (EBMIL, 2017b). A próxima seção, por sua vez, analisa os projetos de cooperação bilateral entre Brasil e Moçambique que se seguiram ao término dessa missão. Conforme apresentado na seção precedente, um dos focos principais da ONUMOZ recaiu no monitoramento do desarmamento das partes em conflito e do cessar-fogo (ONUMOZ, 1992). À luz dessas considerações, a presente seção analisa a atuação do Brasil na missão de peacekeeping em Moçambique, que constitui um primeiro momento no qual o Brasil procurou contribuir para a peacebuilding nesse país. Do ponto de vista metodológico, tanto as operações de peacekeeping quanto os projetos de cooperação técnica podem ser compreendidos como ferramentas à disposição do Estado para a busca de seus objetivos externos, os quais podem ser simbólicos ou materiais (ALSINA JR., 2017, p. 2). Do ponto de vista do campo de estudos das Relações Internacionais, no entanto, essas ferramentas são mais frequentemente analisadas separadamente, uma vez que se referem a temas distintos - as missões de peacekeeping estão mais comumente associadas aos estudos de Segurança e de Defesa, ao passo que a análise de projetos de cooperação técnica guarda maior relação com temas relativos à promoção do desenvolvimento. Assim, a análise sobre a peacebuilding brasileira engloba ambos os conceitos, pois, embora a missão de peacekeeping e os projetos de cooperação técnica sejam aparentemente distintos, as iniciativas brasileiras podem ser analisadas como parte de uma política brasileira mais ampla para a paz em Moçambique, centrada na promoção do desenvolvimento não apenas econômico, mas, também, social.

Nesse sentido, destaca-se que o envio de tropas para missões de peacekeeping no continente africano se enquadra dentro de um "interesse tradicional” do Brasil em apoiar a África, o que foi expresso, por exem- 
plo: (i) na Mensagem $n^{\circ} 823$ do Poder Executivo ao Congresso Nacional, em 5 de novembro de 1993, a qual solicitou ao Congresso a autorização para o envio de tropas brasileiras para a ONUMOZ (CONGRESSO NACIONAL, 1993, p. 25735); e (ii) na Mensagem no 1090, de 1994, por meio da qual o Poder Executivo brasileiro solicitou autorização para o envio de tropas brasileiras à Angola, no contexto da operação de peacekeeping UNAVEM III (CONGRESSO NACIONAL, 1995, p. 2363).

No contexto da ONUMOZ, Fontoura (2005, p. 216) destaca que o Brasil contribuiu com uma força de 300 membros, incluindo 218 militares, 66 policiais e 16 servidores civis. Essa participação, que ocorreu entre janeiro de 1993 e dezembro de 1994, teve um brasileiro no comando do componente militar da missão, o General Lélio Gonçalves Rodrigues da Silva (EBMIL, 2017b). Além disso, o Brasil também contribuiu para o processo eleitoral moçambicano, por meio da atuação de Walter Porto, Assessor do Presidente do Congresso Nacional Brasileiro, que foi juiz das eleições moçambicanas de 1994 (FONTOURA, 2005, p. 216).

No plano da política doméstica do Brasil, Fontoura menciona a formação do Grupo de Trabalho Interministerial como relevante para compreender as motivações do Brasil para atuar no processo de paz moçambicano (FONTOURA, 2005). Esse grupo, composto por representantes de diferentes áreas do governo - Ministério das Relações Exteriores, Ministério da Justiça, Forças Armadas e Congresso Nacional - foi formado por que o governo brasileiro não tinha, naquele momento, uma estrutura governamental dedicada a acompanhar a participação do Brasil em missões de paz (FONTOURA, 2005, p. 222). Esse grupo tinha as seguintes motivações: (i) aumentar a influência brasileira nos órgãos das Nações Unidas relacionados às missões de manutenção da paz; (ii) atualizar a legislação brasileira relacionada ao envio de tropas brasileiras para missões internacionais; (iii) aproveitar as oportunidades de cooperação bilateral que fossem identificadas no contexto da implementação dos processos de paz (FONTOURA, 2005, p. 222). Assim, a participação do Brasil em iniciativas de paz buscou tanto melhorar o status internacional do Brasil quanto identificar novas oportunidades para a cooperação bilateral.

Ainda no contexto interno, para justificar a participação brasileira na ONUMOZ, as seguintes razões foram apresentadas pelo Poder Executivo ao Congresso Nacional, por meio da Mensagem $\mathrm{n}^{\circ} 823$, de 5 de novembro de 1993: (i) responder positivamente a uma demanda do Secretário-Geral das Nações Unidas; (ii) obedecer à Constituição Nacional, que afirma, em seu artigo quarto, o comprometimento do Brasil com a promoção da paz e, também, cumprir com suas obrigações como membro das Nações Unidas; (iii) contribuir para a pacificação do Sul da África; (iv) fortalecer o relacionamento com Moçambique e com países africanos lusófonos; (v) evitar a redução do prestígio internacional do Brasil, na medida em que "a ausência do Brasil nesse esforço de pacificação causaria surpresa e teria repercussões negativas quanto à nossa capacidade de atuação internacional [...]” (CONGRESSO NACIONAL, 1993, p. 25735).

No que se refere à participação das Forças Armadas brasileiras no terreno moçambicano, Sérgio Aguilar (2012, p. 217) argumenta que existe uma "cultura brasileira das operações de paz", a qual é concebida pelo 
5. 0 termo "jeitinho brasileiro" aqui tem uma conotação positiva e remete à forma particular do Brasil promover a paz em países em desenvolvimento, a qual não apenas seria caracterizada pela empatia social e cultural com esses países (AGUILAR, 2012), mas, também, demonstraria empenho com a promoção do desenvolvimento nesses

locais. Essa expressão foi utilizada com outra conotação pelo antropólogo Roberto DaMatta, no livro 0 que faz 0 brasil, Brasil?. Para DaMatta, o "jeitinho brasileiro" se refere à capacidade dos brasileiros de driblar condicionantes legais e institucionais para obter vantagens próprias (DAMATTA, 1986). autor como a contribuição das características culturais do Brasil, como as habilidades de negociação e o comportamento amigável dos brasileiros. Tais características contribuem para o contexto de missões internacionais. Em particular, o autor fornece alguns exemplos sobre como esse "jeitinho brasileiro"s evidenciou-se na ONUMOZ: (i) em uma negociação com ex-guerrilheiros que haviam bloqueado estradas moçambicanas, as tropas brasileiras conseguiram, de forma amigável, negociar a liberação das estradas (AGUILAR, 2012, p. 219); (ii) a pobreza encontrada em Moçambique era uma característica conhecida pelas tropas brasileiras, o que contribuiu para a aproximação entre as tropas brasileiras e a população local (AGUILAR, 2012, p. 221); (iii) algumas práticas culturais brasileiras, como o futebol e a capoeira, contribuíram para a construção de um ambiente de "convivência fraterna" no contexto dessa missão (AGUILAR, 2012, p. 223); (iv) o fato da língua portuguesa ser um idioma comum contribuiu para a formação de um relacionamento positivo entre a equipe brasileira na ONUMOZ e a sociedade moçambicana (AGUILAR, 2012, p. 224).

A despeito de Aguilar ter trazido exemplos concretos da atuação das tropas brasileiras, com base em entrevistas com militares que estiveram no terreno, é necessário questionar em que medida essa atuação do Brasil em Moçambique promoveu a integração entre as diferentes forças presentes em campo para a promoção, nesse país, de uma forma de paz voltada à promoção do desenvolvimento econômico e social dos moçambicanos. A despeito da ideia de "jeitinho brasileiro", não houve uma doutrina de integração que coadunasse a atuação dos componentes militar, civil e policial no terreno (USP, 2017). Além disso, conforme mencionado nas seções precedentes, o mandato da ONUMOZ não mencionou diretamente o conceito de peacebuilding (ONUMOZ, 1992).

Dessa forma, se, por um lado, o Brasil manifestou interesse para a atuação em Moçambique em diversas dimensões, na prática, a atuação do Brasil no contexto da ONUMOZ esteve associada, preponderantemente, à dimensão militar, pois não houve, no mandato dessa missão, a previsão de sinergias entre militares e atores civis engajados em projetos para o desenvolvimento. Visto dessa perspectiva, é possível afirmar que, embora os militares no terreno tenham apresentado formas culturais de interação caracterizadas como um "jeitinho brasileiro", essas características não constituíram indícios de que houve uma política do Estado brasileiro comprometida com a promoção da paz por meio do desenvolvimento no contexto da implementação da ONUMOZ, haja vista as condicionantes impostas pelo mandato da ONUMOZ. Como forma de ampliar as discussões para o período posterior à ONUMOZ, a terceira seção avalia a implementação de projetos de cooperação técnica para o desenvolvimento entre o Brasil e Moçambique.

A cooperação técnica entre Brasil e Moçambique (1992-2010): limites do elo entre paz e desenvolvimento

A análise da atuação do Brasil no processo de paz de Moçambique deve passar, também, pela análise dos acordos de cooperação bilateral entre os dois países. De acordo com Mendonça e Faria $(2015$, p. 8), as ini- 
ciativas brasileiras no contexto da cooperação técnica para o desenvolvimento podem ser associadas às seguintes motivações: (i) a necessidade de promoção do desenvolvimento sustentável, em particular no contexto da solidariedade existente entre países em desenvolvimento; (ii) uma forma de fortalecer os laços entre países latino-americanos e africanos; (iii) a proximidade histórica e cultural com alguns dos países com os quais o Brasil mantém projetos de cooperação técnica.

Nesse contexto, Mendonça e Faria (2015, p. 8) argumentam que, desde a criação da Agência Brasileira de Cooperação, em 1987, houve uma mudança no perfil da Cooperação Técnica para o Desenvolvimento do Brasil, na medida em que a diplomacia brasileira questionou o discurso de assimetria entre países receptores e doadores, propondo, ao invés disso, parcerias na forma da Cooperação Sul-Sul. Contudo, esses autores afirmaram que a Cooperação Técnica para o Desenvolvimento do Brasil baseia-se nas práticas e nas expectativas que foram consolidadas em organizações multilaterais e fóruns com uma longa experiência na cooperação para o desenvolvimento (MENDONÇA; FARIA, 2015, p. 7). Essa afirmação traz questionamentos sobre a ideia segundo a qual o Brasil, um país em desenvolvimento, tem maior proximidade com as sociedades locais e realidades de seus parceiros em desenvolvimento (NGANJE, 2013). No caso da cooperação técnica entre Brasil e Moçambique, o fato de o Brasil ser um país em desenvolvimento não constituiu motivação suficiente para produzir uma política de paz marcada pela articulação entre a participação brasileira na ONUMOZ e os sucessivos projetos de cooperação entre o Brasil e Moçambique, nos quais o desenvolvimento pudesse ser identificado como um link de coesão. Essa afirmação pode ser evidenciada por meio da análise dos governos brasileiros de Fernando Henrique Cardoso (1995-2002) e Luiz Inácio Lula da Silva (2003-2010) relativamente ao continente africano, cujos mandatos estão compreendidos no período que se seguiu à retirada da ONUMOZ.

Mendonça e Faria (2015, p. 8) argumentam que houve uma "exclusão" da África das prioridades da Política Externa Brasileira (PEB) durante o governo FHC. De acordo com esses autores, embaixadas brasileiras foram fechadas em diversos países, como na Etiópia, Tanzânia, Camarões, República Democrática do Congo, Togo e Zâmbia. José Flávio Sombra Saraiva (2012, p. 50) corrobora essa visão ao afirmar que, durante a era FHC, houve a "ampliação do silêncio nas relações Brasil-África", embora persistissem as relações comerciais e a presença de empresários brasileiros em países do continente.

Ao contrário do período anterior, o governo de Lula (2003-2010) trouxe a renovação do interesse do Brasil pela África, na medida em que buscou materializar esse interesse em bases dotadas de maior solidez (IPEA/BANCO MUNDIAL, 2011, p. 3). Nesse governo, áreas como o desenvolvimento agrícola e a saúde, entre outras, receberam maior atenção entre os 49 projetos de cooperação desenvolvidos pelo Brasil (conforme a Tabela 1, abaixo). Durante esse governo, destacaram-se os seguintes projetos: 1) de instalação de uma fábrica de medicamentos antirretrovirais em Moçambique, a partir de 2008; e 2) da cooperação trilateral entre Brasil, Japão e Moçambique, no contexto do ProSavana (IPEA/BANCO 
MUNDIAL, 2011). Segundo Almeida (2016, p. 58), a fábrica de medicamentos antirretrovirais, cuja propriedade é do governo moçambicano, evidenciou um diferencial da cooperação brasileira, na medida em que possibilitou maior autonomia ao país africano para a produção de medicamentos de combate ao HIV/AIDS. A cooperação trilateral no contexto do ProSavana, por sua vez, representou a aplicação da experiência nipo-brasileira com o Cerrado na Savana africana. Contudo, esse projeto vem sendo objeto de críticas, pois o modelo implementado no Brasil, ao ser exportado para Moçambique, poderia gerar uma série de problemas, como o surgimento de sem-terras, o aumento da pobreza e a produção de desequilíbrios ecológicos (ALMEIDA, 2016, p. 63).

É importante destacar a natureza e a especificidade de alguns desses projetos de cooperação com Moçambique. De acordo com o estudo do IPEA (2010), o Brasil priorizou, no governo Lula, projetos estruturantes com os países africanos, por serem mais abrangentes e apresentarem efeitos multiplicadores de longo prazo. Para José Roberto Ferreira e Luiz Eduardo Fonseca (2017), a cooperação estruturante na área de saúde, por exemplo, visava ao fortalecimento institucional dos sistemas de saúde dos países parceiros e à formação de recursos humanos qualificados. Dessa forma, segundo os autores, o Brasil acompanhava uma reflexão desenvolvida no âmbito da Organização para a Cooperação e Desenvolvimento Econômico (OCDE), centrada na necessidade de rediscutir a eficácia do modelo tradicional de cooperação conduzido pelos países desenvolvidos e centrado na ajuda e no combate às doenças. A partir da reunião da OCDE de 2005, em Paris, sugeriu-se a necessidade de se estabelecer um planejamento conjunto com o país parceiro, com o propósito de levar os responsáveis locais a se apropriarem dos avanços promovidos pela cooperação. Para os autores, a cooperação estruturante visava romper com a tradicional negociação prescritiva e característica da relação doador-receptor.

De forma mais ampla, conforme observa Saraiva (2010, p. 180), as relações entre o Brasil e os países africanos foram reforçadas no governo Lula, de maneira a explorar não apenas as dimensões comercial e de investimentos, mas também as relações com esses países em temas como a cooperação para o desenvolvimento. Entre 2006 e 2010, o orçamento anual da Agência Brasileira de Cooperação passou de 18,7 milhões para 52,26 milhões de reais (MRE, 2010b, p. 9) e, em 2009, metade desse montante destinou-se a países africanos (MRE, 2010b, p. 10; CALL; ABDENUR, 2017, p. 11). José Flávio Sombra Saraiva (2010, p. 180) destaca que a política externa do Brasil para a África no início do século XXI coadunou esforços diplomáticos a esforços no âmbito econômico, de forma a envolver também empresários na agenda internacional.

Nesse sentido, Pedro Seabra (2014, p. 81) destaca que o Brasil deu maior destaque a mecanismos de cooperação, colocando iniciativas como, por exemplo, da Agência Brasileira de Cooperação (ABC), no centro da estratégia da política externa nacional. No caso de Moçambique, a mudança da PEB para esse país entre os governos de FHC e de Lula da Silva pode ser observada por meio da análise do número e do escopo dos projetos de cooperação técnica bilateral, de 1995 a 2010 (MRE, 2017b). Os dados evidenciam que cinco acordos de cooperação técnica foram assi- 
nados entre Brasil e Moçambique durante os anos FHC, ao passo que, durante os anos Lula, 49 acordos bilaterais desse tipo foram firmados. Com relação ao escopo dos projetos, a Tabela 1 demonstra que houve um número relativamente reduzido de projetos de cooperação no período posterior ao término da ONUMOZ, na comparação com o governo de Lula da Silva.

Tabela 1- Acordos de Cooperação entre Brasil e Moçambique de 1995 a 2010

\begin{tabular}{l|c|c}
\hline Áreas de Cooperação & FHC & Lula da Silva \\
\hline Agricultura/Agropecuária & & 4 \\
\hline Alimentação & & 1 \\
\hline Biocombustíveis & & 1 \\
\hline Capacitação profissional/científica e tecnológica & 4 \\
\hline Combate a Entorpecentes e a Transações Fraudulentas & & 1 \\
\hline Comunicação Social & & 1 \\
\hline Cooperação Acadêmica & & 1 \\
\hline Cultural & & 6 \\
\hline Desenvolvimento Urbano & & 3 \\
\hline Educação e Alimentação & & 2 \\
\hline Educacional & 3 & 1 \\
\hline Esportes & & 3 \\
\hline Florestas & & 1 \\
\hline Fortalecimento Institucional & & 3 \\
\hline Mineração & 1 & 1 \\
\hline Obras Públicas & & 1 \\
\hline Saúde & & 1 \\
\hline Segurança Pública & & 2 \\
\hline Terras e Mapeamento & & 1 \\
\hline Turismo & & 1 \\
\hline
\end{tabular}

Fonte: Elaboração própria com base em MRE (2017b)

Vale destacar, ainda, que Mendonça e Faria (2015, p. 17) organizaram uma tabela semelhante com dados de todos os acordos de cooperação entre o Brasil e países africanos, de forma a evidenciar uma perspectiva comparativa entre os governos de FHC e de Lula. Nesse trabalho, os autores demonstram que houve um incremento, na passagem dos governos de FHC a Lula, do número e do escopo dos projetos de cooperação entre o Brasil e países africanos, de forma geral. Ao considerar as distintas abordagens dos governos de FHC e de Lula no tocante ao conceito de desenvolvimento, verifica-se que os projetos de cooperação para o desenvolvimento para Moçambique obedeceram a condicionantes específicos de política externa brasileira desses dois governos. Dessa forma, evidencia-se que as descontinuidades existentes entre a promoção da paz e o desenvolvimento econômico e social no período 1992-2010 podem ser compreendidas a partir da APE.

Marcelo Passini Mariano e Haroldo Ramanzini Júnior (2012, p. 27) argumentaram que o conceito de desenvolvimento, pilar central da política externa brasileira, modifica-se ao longo do tempo. Assim, 
os autores destacam a existência de diferenças entre os governos brasileiros quanto à compreensão e à operacionalização do conceito de desenvolvimento (MARIANO; RAMANZINI JÚNIOR, 2012, p. 27). Para Bernal-Meza (2002), o governo de Fernando Henrique Cardoso (19952002) apresentou novos entendimentos relativamente ao conceito de desenvolvimento. Embora o Brasil tenha apresentado, nesse período, um incremento do multilateralismo no plano externo, essa ação mostrou nítida inclinação a fóruns econômicos internacionais (BERNAL-MEZA, 2002, p. 54). Segundo esse autor, começou a se fortalecer, no governo de Fernando Henrique, a ideia de que as Nações Unidas deveriam ter um enfoque para o tratamento de questões humanitárias e de segurança, de forma que houve uma relativa dissociação entre as agendas de paz e de segurança, por um lado, e de desenvolvimento, por outro (BERNAL-MEZA, 2002, p. 54). Diferentemente do governo de Fernando Henrique Cardoso, Carlos Ribeiro Santana (2006, p. 13) afirma que, no governo Lula da Silva (2003-2010), os debates sobre a paz e segurança estiveram diretamente associados às temáticas do desenvolvimento econômico e da justiça social. Nesse sentido, Santana destacou que "a consecução do objetivo nacional de desenvolvimento com inclusão social reflete a melhor maneira de resumir os aspectos gerais da política externa do governo Lula" (SANTANA, 2006, p. 13). Assim, Santana (2006, p. 13) evidenciou que a agenda de desenvolvimento, para o governo Lula, constituiu uma premissa básica para a consolidação da agenda de paz e de segurança.

Diferentes autores, portanto, revelaram que os governos brasileiros apresentaram entendimentos distintos relativamente à noção de desenvolvimento. Enquanto os governos de Fernando Collor de Mello (19901992) e de Fernando Henrique Cardoso apresentaram perspectivas de desenvolvimento mais fortemente calcadas no âmbito econômico (MARIANO, 2015, p. 122; SALLUM JR., 2011, p. 263-264; BERNAL-MEZA, 2002, p. 54; MARIANO ; RAMANZINI JÚNIOR, 2012, p. 28), os governos de Itamar Franco (1992-1994) e de Luís Inácio Lula da Silva buscaram fortalecer, no plano internacional, um conceito de desenvolvimento mais fortemente associado à promoção da "justiça social" (BERNAL-MEZA, 2002, p. 52; SANTANA, 2006, p. 10-13; HIRST; PINHEIRO, 1995, p. 11). Em consequência dessa alternância de perspectivas de desenvolvimento, é possível afirmar que houve variações na atuação do Brasil em suas iniciativas para a promoção da paz em Moçambique, uma vez que a ideia de desenvolvimento está no cerne do conceito de peacebuilding, conforme exposto na Introdução deste artigo.

Assim, embora o relacionamento entre Brasil e Moçambique seja resultado de um quadro mais amplo da Política Externa Brasileira para a África, é possível argumentar que houve uma descontinuidade da Política Externa Brasileira para a paz em Moçambique. Isso é verdade na medida em que o governo de Fernando Henrique Cardoso deu pouca ênfase à cooperação bilateral com Moçambique, em um momento no qual as preocupações com o desenvolvimento moçambicano deveriam receber mais atenção do Brasil. Partindo dessa perspectiva, o período de término de uma missão de peacekeeping, como a ONUMOZ, ensejaria a ampliação dos esforços para a promoção do desenvolvimento. $\mathrm{O}$ aumento dos proje- 
tos de cooperação técnica seria uma evidência desses esforços. A análise da Tabela 1, entretanto, demonstrou que áreas cruciais para a promoção do desenvolvimento não foram objeto de acordos de cooperação bilateral durante o governo de Fernando Henrique Cardoso, como é o caso das áreas da saúde, da agricultura, da alimentação e da ciência e tecnologia. Ressalte-se, ainda, que a cooperação durante o governo de FHC contemplou projetos nas áreas de mineração, em 1997, e de segurança pública e educação, cujos acordos ocorreram somente em 2001. Dessa forma, verifica-se que o período posterior ao término da ONUMOZ não registrou implementação sistemática de projetos capazes de trazer a paz por meio do desenvolvimento.

Autores, como Oliver Richmond e Ioannis Tellidis (2013, p. 2-4), argumentaram que a atual crise da paz liberal abriu espaço a atores, como o Brasil, que desenvolveram suas próprias agendas para a peacebuilding. Considerando as relações de proximidade entre os países do Sul Global, essas agendas deveriam enfatizar as sociedades locais e, por extensão, o tema do subdesenvolvimento, que se faz presente na vida diária dessas populações (RICHMOND; TELLIDIS, 2013, p. 2-4). Essa abordagem seria consistente com uma perspectiva crítica de peacebuilding, a qual compreende que a promoção da paz deve estar, necessariamente, relacionada ao diálogo com as sociedades locais com o propósito de compreender os conflitos (MAC GINTY, 2011). Durante o período analisado neste artigo, é possível identificar dois momentos: nos anos 1990, o Brasil relacionou o tema da paz às missões de peacekeeping e desenvolveu um número pequeno de projetos de cooperação para o desenvolvimento de Moçambique; durante o governo Lula, o Brasil compreendeu a necessidade da cooperação para o desenvolvimento quando coordenou 49 projetos de cooperação com Moçambique. Portanto, a atuação brasileira na promoção da paz em Mocambique é caracterizada por limites relativos à associação entre construção da paz e promoção do desenvolvimento. Esses limites corroboram a visão de Ramon Blanco (2016), segundo a qual a inserção brasileira no debate internacional sobre peacebuilding deveria ser mais qualificada, e isso demandaria não apenas a contribuição com tropas, mas, também, "....aglutinar, de modo integrado e coordenado, diferentes tipos de atores e instituições em sua atuação na construção da paz internacional” (BLANCO, 2016, p. 23).

Dessa forma, não obstante o Brasil apresente uma retórica diplomática que enfatiza a "(...) interdependência entre a segurança e o desenvolvimento como elemento indispensável à paz sustentável” (MRE, 2017a), no caso de Moçambique, verificou-se que essa interdependência não se refletiu na produção de uma política externa brasileira para a paz que enfatizasse a interligação entre dois dos mais presentes instrumentos dessa política: a participação brasileira em missões de peacekeeping e os projetos de cooperação técnica para o desenvolvimento.

Considerações finais

No caso de Moçambique, a APE evidencia que a distribuição heterogênea de projetos de cooperação técnica bilateral pode ser interpretada como o resultado das diferentes abordagens de desenvolvimento dos 
governos brasileiros de 1992 a 2010. Esse caso, portanto, enseja o debate sobre a relevância do Brasil de promover uma inserção internacional que seja o reflexo de uma maior sinergia entre os diferentes instrumentos que compõem o portfolio da Política Externa Brasileira, como é o caso das missões de peacekeeping e dos projetos de cooperação para o desenvolvimento. Assim, essa aproximação pode contribuir para que a atuação internacional do Brasil para a promoção da paz reforce o desenvolvimento, em suas dimensões econômica e social, como seu fio condutor.

Dessa forma, verificou-se aqui que, embora o Brasil enfatize a importância do desenvolvimento para a promoção da paz - o que justificaria o link entre as operações de paz e os acordos de cooperação técnica - não houve continuidade na promoção do desenvolvimento entre 1995 e 2002, período posterior ao término da ONUMOZ, no qual foram realizados apenas cinco projetos de cooperação técnica entre Brasil e Moçambique. De fato, a análise da concentração temática de projetos evidenciou que apenas as áreas de mineração, educação e segurança pública foram contempladas por projetos de cooperação no governo de Fernando Henrique Cardoso, sendo que os projetos de educação e de segurança pública tiveram início somente em 2001 - seis anos após o término do mandato da ONUMOZ.

Esse fato evidencia que, no caso de Moçambique, não é possível afirmar que houve uma política externa brasileira voltada à articulação sistemática entre a paz e o desenvolvimento, pois as diferentes compreensões dos governos brasileiros nesse último tema fizeram que a promoção da paz em Moçambique tenha sido operacionalizada, essencialmente, no contexto da missão de peacekeeping. A cooperação para o desenvolvimento foi enfatizada apenas posteriormente, no contexto do governo Lula, por meio do incremento dos projetos técnicos bilaterais. Assim, os resultados deste artigo contrariam a suposição de que o Brasil, como um país em desenvolvimento, enfatizou, na prática de suas relações com Moçambique entre 1992 e 2010, o link entre paz e desenvolvimento.

Referências

A/47/277. An Agenda for Peace. 17 de Junho de 1992. Disponível em: $<$ http://daccess-dds-y.un.org/ doc/UNDOC/GEN/N92/259/61/PDF/N9225961.pdf?OpenElement>. Acesso em: 23 maio 2017.

ABDENUR, Adriana E.; MARCONDES, Danilo. Democratization by Association? Brazil's Social Policy Cooperation in Africa. Cambridge Review of International Affairs, Vol. 29, Issue 4, p. 1542-1560, 2016.

AGUILAR, S. Uma cultura brasileira de missões de paz. In: BRIGAGÃO, Clóvis; FERNANDES, Fernanda. (org.) Diplomacia brasileira para a paz. Brasília: FUNAG, 2012.

ALMEIDA, Elga Lessa de. Entre o discurso solidário e a ação pragmática da cooperação brasileira em Moçambique: os casos dos projetos de implantação da fábrica de medicamentos antirretrovirais e o ProSavana. Cadernos CRH, Salvador, vol. 29, nº 76, p. 53-68, Abril, 2016.

ALSINA JUNIOR, João Paulo S.. Grand Strategy and Peace Operations: the Brazilian Case. Rev. Bras. Polít. Int., Brasília, v. 60, n. 2, 2017, p. 1-22.

BANCO MUNDIAL. Mozambique. Disponível em:< https://goo.gl/0foU4K>. Acesso em: 22 ago. 2017.

BERNAL-MEZA, Raúl. A política exterior do Brasil: 1990-2002. Rev. Bras. Polít. Int., Brasília, v. 45 , n. 1, 2002, p. 36-71.

BLANCO, R. A miopia brasileira na construção da paz internacional. Le Monde Diplomatique Brasil, fev. 2016. 
BOWKER, T., KAMM, S., SAMBO, A. Mozambique’s Invisible Civil War. Disponível em:< http://foreignpolicy.com/2016/05/06/mozambiques-invisible-civil-war-renamo-frelimo-dhlakama-nyusi/>. Acesso em: 23 maio 2017.

BRACEY, D. O Brasil e as Operações de Manutenção da Paz da ONU: Os Casos do Timor Leste e Haiti. Contexto Internacional, Rio de Janeiro, vol. 33, n. 2, 2011, p. 315-331.

BRITANNICA. Zimbábue. Disponível em: <https://goo.gl/FounNN>. Acesso em: 23 maio 2017.

CALL, Charles T. e ABDENUR, Adriana E. A "Brazilian way"? Brazil's approach to peacebuilding. Disponível em: <https://goo.gl/yokxCo >. Acesso em: 4 jun. 2017.

CONGRESSO NACIONAL. Decreto Legislativo 15/1994. Disponível em: $<$ https://goo.gl/MurasJ> . Acesso em: 23 maio 2017.

CONGRESSO NACIONAL. Mensagem n ${ }^{\circ}$ 1090, de 1994. In: Diário do Congresso Nacional. Ano L - N. 30. sexta-feira, 24 de fevereiro de 1995.

CONGRESSO NACIONAL. Mensagem n ${ }^{\circ} 823$ do Poder Executivo ao Congresso Nacional, em 5 de novembro de 1993. In: Diário do Congresso Nacional. Ano XLVIII - $\mathrm{N}^{\circ} 196$, terça-feira, 30 de novembro de 1993. Disponível em: <https://goo.gl/mVRfME>. Acesso em: 4 jun. 2017.

CRAVINHO, J. Mozambique recent history. In: African South of the Sahara. New York: Routhledge, 2004, p. 741-746.

DAMATTA, Roberto. O que faz o brasil, Brasil? Rio de Janeiro: Rocco, 1986.

DE CONING, C. e PRAKASH, C. Peace Capacities Network Synthesis Report Rising Powers and Peace Operations. Oslo: Norwegian Institute of International Affairs, 2016.

EBMIL. Atuação do Brasil em Missões de Paz. Disponível em: $<$ https://goo.gl/94aoPB $>$. Acesso em: 23 maio 2017. (2017a)

EBMIL. United Nations Operation in Mozambique (ONUMOZ). Disponível em: www.eb.mil. br/onumoz. Acesso em: 23 maio 2017. (2017b).

FERREIRA, José Roberto; FONSECA, Luiz Eduardo. Cooperação estruturante, a experiência da Fiocruz. Ciência \& Saúde Coletiva, Rio de Janeiro, vol. 22, n. 7, 2017, p. 2129-2133.

FONTOURA, P. R. C. T. da. O Brasil e as Operações de Manutenção da Paz das Nações Unidas. Brasília, FUNAG, 2005.

GALTUNG, Johan. Three Approaches to Peace: Peacekeeping, peacemaking and peacebuilding. In: Peace, War and Defence, Essays in Peace Research, vol. 2, 1976, p. 282-304.

GPA. Mozambique General Peace Agreement. In: The Mozambican Peace Process in Perspective. London, Conciliation Resources, 1992.

HIRST, M. e PINHEIRO, L. A Política Externa do Brasil em dois tempos. Rev. Bras. Polít. Int., Brasília, vol.1, n. 38, 1995, p.5-23.

IPEA/ABC. Cooperação brasileira para o desenvolvimento internacional: 2005-2009. Brasília: Ipea: ABC, 2010, 78 p. Disponível em:< https://goo.gl/1oxWWZ>. Acesso em: 03 maio 2018.

IPEA/BANCO MUNDIAL. Ponte sobre o Atlântico Brasil e África Subsaariana: parceria Sul-Sul para o crescimento. Brasília: IPEA/Banco Mundial, 2011.

JACKSON, R. Internal War, International Mediation, and Non-Official Diplomacy, Lessons from Mozambique. Journal of Conflict Studies, vol. 25, n. 1, jan. 2005.

JENKINS, R. Peacebuilding. From Concept to Commission. New York: Routledge, 2013.

JENTZSCH, C. Here are 4 reasons why Mozambique isn't a post-war success story. Disponível em: $<$ https://goo.gl/Gho58W>. Acesso em: 23 maio 2017.

KEMER, T.; PEREIRA, A. E.; BLANCO, R. A construção da paz em um mundo em transformação:o debate e a crítica sobre o conceito de peacebuilding. Rev. Sociol. Polit., Curitiba, vol. 24, n. 60, dez. 2016, p. 137-150.

KENKEL, K. M. O peacebuilding do Brasil na África e no Haiti: uma alternativa à paz liberal, ou só maquiagem? Anais do $4^{\circ}$ Encontro Nacional da Associação Brasileira de Relações Internacionais, Belo Horizonte, 2013.

MAC GINTY, R. International Peacebuilding and Local Resistance, Hybrid Forms of Peace. New York: Palgrave, 2011.

MACHADO, João Guilherme Rocha; PAMPLONA, João Batista. A ONU e o desenvolvimento econômico: uma interpretação das bases teóricas da atuação do PNUD. Economia e Sociedade, Campinas, vol. 17, n.1 , 2008, p. 53-84. 
MALAQUIAS, A. V. UN Peace Operations In Lusophone Africa: Contrasting Strategies And Outcomes. Journal of Conflict Studies, vol. 18, n. 2, 1998.

MARIANO, Marcelo Passini. A política externa brasileira e a integração regional: uma análise a partir do Mercosul. São Paulo: Editora da Unesp Digital, 2015.

MARIANO, Marcelo Passini; RAMANZINI JUNIOR, Haroldo. Uma análise das limitações estruturais do Mercosul a partir das posições da política externa brasileira. Rev. Sociol. Polit., Curitiba, vol. 20, n. 43, out. 2012, p. 23-41.

MENDONCA JUNIOR, Wilson; FARIA, Carlos Aurélio Pimenta de. A cooperação técnica do Brasil com a África: Comparando os governos Fernando Henrique Cardoso (1995-2002) e Lula da Silva (2003-2010). Rev. Bras. Polít. Int., Brasília, vol. 58, n. 1, 2015, p. 5-22.

MILANI, Carlos R. S. e PINHEIRO, Leticia. Política externa brasileira: os desafios de sua caracterização como política pública. Contexto Internacional, Rio de Janeiro, vol. 35, n. 1, 2013, p. 11-41.

MRE. Brazilian Foreign Policy Handbook: Positions Adopted by Brazil in 2008-2009. Brasília: FUNAG, 2010a.

MRE. Agência Brasileira de Cooperação. Apresentação do Ministro Marco Farani, Diretor da ABC, no Centro Brasileiro de Relações Internacionais (CEBRI), Rio de Janeiro Disponível em: $<$ https://goo.gl/hg24Cm>. Acesso em: 5 jun. 2017.

MRE. Brazil and the UN Peacekeeping Missions. Disponível em: $<$ https://goo.gl/fZv5S8 $>$. Acesso em: 23 maio 2017a.

MRE. Sistema de Atos Internacionais. Disponível em: $<$ http://dai-mre.serpro.gov.br/pesquisa_ato_bil.> Acesso em: 23 maio de 2017b.

MSF. Malawi: Humanitarian standards not reachable for more than 5,800 Mozambican refugees in Kapise camp. Disponível em:< https://goo.gl/9Y946m.> Acesso em: 23 maio 2017.

NAÇÕES UNIDAS. Resolução 782 do Conselho de Segurança das Nações Unidas. Disponível em: <https://goo.gl/HGgocY>. Acesso em: 23 maio 2017.

NAÇÕES UNIDAS. Resolução 797 do Conselho de Segurança das Nações Unidas. Disponível em< https://goo.gl/sbjwts $>$. Acesso em: 23 maio 2017.

NEVES, G. M. S. Comissão das Nações Unidas para Consolidação da Paz: perspectiva brasileira. Brasília: FUNAG, 2009.

NGANJE, F. Peacebuilding from below: the role of decentralized south-south cooperation in Africa. The Southern Voices Network: Research Paper nº 1. Wilson Center, 2013.

ONUMOZ. Disponível em: <https://goo.gl/KuaxBG>. Acesso em: 23 maio 2017.

PBSO. Peacebuilding: An Orientation. Disponível em: $<$ https://goo.gl/BselW $>$. Acesso em: 23 maio 2017.

PNUD. Human Development Report. New York: Oxford University Press, 1990.

REFWORLD. Zimbabwe: The Central Intelligence Organization (CIO), including its structure and branches and whether its members commit human rights abuses. Disponível em: $<$ http://www.refworld.org/docid/3df4bece4.html>. Acesso em: 23 maio 2017.

REPPELL, L.; ROZEN, J., DE CARVALHO, G. Planning for peace Lessons from Mozambique's peacebuilding process. Institute for Security Studies 2016. Disponível em: $<$ https:// www.issafrica.org/uploads/Paper291.pdf>. Acesso em: 23 maio 2017.

RICHMOND, O. P. e TELLIDIS, I. The BRICS and international peacebuilding and statebuilding. Norwegian Peacebuilding Resources Centre (NOREF), 2013.

RUPIYA, M. Historical Context: War and Peace in Mozambique. In: The Mozambican Peace Process in Perspective. Issue 3. London: Conciliation Resources, 1998.

SALLUM JR., Brasilio. Governo Collor: o reformismo liberal e a nova orientação da política externa brasileira. Revista Dados, Rio de Janeiro, vol. 54, n.2, 2011, p. 259-288.

SANTANA, Carlos Ribeiro. Política externa em perspectiva: um balanço sobre a diplomacia dos presidentes Collor, Itamar, Cardoso e Lula. Carta Internacional, São Paulo, nov. de 2006.

SARAIVA, José Flávio Sombra. The new Africa and Brazil in the Lula era: the rebirth of Brazilian Atlantic Policy. Rev. Bras. Polít. Int., Brasília, v. 53, dez. 2010, p. 169-182.

SARAIVA, José Flávio Sombra. África parceira do Brasil Atlântico: relações internacionais do Brasil e da África no início do século XXI. Belo Horizonte: Fino Traço, 2012. 
SEABRA, Pedro. A harder edge: reframing Brazil's power relation with Africa. Rev. Bras. Polít. Int., Brasília, v. 57, n. 1, 2014, p. 77-97.

USP. Workshop Brasil e Operações de Paz da ONU. Disponível em: <http://www.eventos. usp.br/?events=workshop-aborda-brasil-e-operacoes-de-paz-da-onu>. Acesso em: 5 jun. 2017.

UZIEL, E. O Conselho de Segurança, as Missões de Paz e o Brasil no Mecanismo de Segurança Coletiva das Nações Unidas. Brasília: FUNAG, 2015.

VARELLA, Raquel. "Um, dois, três MFA...”: o Movimento das Forças Armadas na Revolução dos Cravos - do prestígio à crise. Revista Brasileira de História, São Paulo, vol. 32, n. 63, 2012, p. 403-425.

VISENTINI, Paulo Fagundes. As revoluções africanas: Angola, Moçambique e Etiópia. São Paulo: UNESP, 2012. 